\title{
Rapid Bridge Deck Condition Assessment Using Three- Dimensional Visualization of Impact Echo Data
}

\author{
Nenad GUCUNSKI ${ }^{1}$, Zhe WANG ${ }^{2}$, Tong FANG ${ }^{2}$, Ali MAHER ${ }^{1}$ \\ ${ }^{1}$ Rutgers University, Piscataway, New Jersey, U.S.A., Gucunski@rci.rutgers.eduT \\ 2 Siemens Corporate Research, Princeton, New Jersey, U.S.A.
}

\begin{abstract}
Seismic/ultrasonic methods can be successfully used in condition assessment of bridge decks by evaluating changes in material characteristics and detection of development of defects and zones of deterioration. The impact echo method is of special benefit in evaluation of corrosion induced deck delamination due to its nondestructive nature and ability to detect delaminated zones at various stages of deterioration: from initial to progressed and developed. The traditional approach in condition assessment of bridge decks by impact echo is based on a review of individual test point records. A new approach based on three dimensional data visualization is proposed. The developed three dimensional visualization platform allows both the advanced presentation and an automated interpretation of impact echo data. The data presentation is provided in terms three dimensional translucent visualizations of reflectors in a bridge deck section, and horizontal and vertical cross sections through all distinctive zones, including a zone of delamination. The associated interpretation platform allows both the overall assessment of the condition of the deck, through cumulative distributions of reflection intensity of different reflective layers, and identification of deteriorated zones of the deck for repair or rehabilitation in an efficient and intuitive way.
\end{abstract}

\section{Résumé}

Les méthodes vibratoires/ultrasonores peuvent être utilisées avec succès dans l'évaluation de l'état des tabliers d'ouvrages, en permettant de détecter et d'évaluer les changements de caractéristiques des matériaux, les défauts associés et le développement de zones de dégradation. La méthode d'impact écho apporte des avantages spécifiques en matière d'évaluation de la délamination induite par la corrosion des armartures, en raison de son caractère non destructif et la capacité de détecter les zones de délamination à divers stades de dégradation. L'approche traditionnelle d'évaluation de l'état des tabliers d'ouvrages par l'impact d'écho est fondée sur un examen de chaque point d'enregistrement de l'essai. Une nouvelle approche fondée sur la visualisation de données en trois dimensions est proposée. La plateforme de visualisation en trois dimensions permet des avancées majeures en termes de présentation et d'interprétation automatique des données d'impact d'écho. La présentation des données est fournie sous la forme d'une visualisation translucide d'un réflecteur en trois dimensions, suivant chaque section horizontale ou verticale du tablier, et à travers toutes les sections distinctes, y compris les zones de délamination. La plate-forme d'interprétation associée permet à la fois l'évaluation globale de l'état du pont, par le biais de distributions cumulatives de l'intensité de réflexion des différentes couches réfléchissantes, et l'identification des zones dégradées du pont pour la réparation ou la réhabilitation d'une manière efficace et intuitive. La nouvelle approche par visualisation permet une évaluation de l'état du tablier proche des résultats obtenus à partir de l'approche traditionnelle.

\section{Keywords}

Delamination, corrosion, ultrasonics. 


\section{Introduction}

One of the most common problems in concrete bridge decks is a corrosion induced deck delamination. Impact echo (IE), together with other ultrasonic seismic techniques, like ultrasonic body-wave (UBW) and ultrasonic surface-wave (USW), has been successfully implemented in comprehensive evaluation of bridge decks and slabs [1-4]. It has been demonstrated that IE can detect and assess delaminations at various deterioration stages. Significant improvements to the automation of the evaluation process are expected to come from neural network algorithms developed using finite element simulations of ultrasonic testing on delaminated bridge decks [3], and improved data visualization [5]. The objective of the paper is to present an impact echo data visualization and interpretation framework for the assessment of concrete bridge decks. IE data visualization and to it related interpretation techniques can be used to both enhance and simplify the interpretation of results of testing on delaminated bridge decks. The proposed data visualization provides practicing engineers a more intuitive approach to bridge deck evaluation.

\section{Traditional Condition Assessment by Impact Echo}

The IE test is conducted using an impact source and a single nearby receiver. Because of a significant contrast in rigidity of concrete and air at the bottom of the deck, the compression (P) wave is practically entirely reflected back towards the deck surface. The frequency of the reflection, called return frequency, can be identified in the response spectrum of the recorded signal. The return frequency $\left(f_{r}\right)$ and the previously determined compression wave velocity $\left(\mathrm{V}_{\mathrm{p}}\right)$ are used to measure the depth of the reflector, in this case the deck thickness, using a simple relationship $\mathrm{T}=\mathrm{V}_{\mathrm{p}} / 2 \mathrm{f}_{\mathrm{r}}$. Depending on the extent and continuity of the delamination, the partitioning of energy of elastic waves may vary and different grades can be assigned to the tested section of a deck. In a case of a sound deck (good condition), a peak in the response spectrum corresponding to the full depth of the deck, can be observed. In a case of a delaminated deck, reflections of the P-wave occur at shallower depths, causing a shift in the response spectrum towards higher frequencies. Initial delamination (fair condition) is described as occasional separations between the two deck zones. It can be identified through the presence of two peaks, the first corresponding to reflections from the bottom of the deck, the second to reflections from the delamination.

Progressed delamination (poor condition) is characterized by a single peak at a frequency corresponding to a reflector depth that is shallower than the deck thickness, indicating that little or no energy is being propagated towards the bottom of the deck. Finally, in a very severe case of a wide delamination (serious condition), the dominant response of the deck to an impact is characterized by a low frequency response of flexural mode oscillations of the upper delaminated portion of the deck. This response is almost always in the audible frequency range, unlike the response of the deck in fair or poor conditions that may be in the ultrasonic range. Because it is significantly lower than the return frequency for the deck bottom, it produces an apparent reflector depth that is larger than the deck thickness. The four described grades are illustrated later in Figure 4.

\section{Impact Echo Data Visualization}

While the primary objective of IE testing is to detect dominant reflectors, according to the reflector depth relationship previously defined, a unique thickness or depth can be correlated to every component of the frequency spectrum. This is illustrated in Figure 1 by a frequency spectrum and to it corresponding thickness or depth spectrum. The thickness spectrum enables simple data interpretation, because positions of dominant and secondary peaks 
describe the energy partitioning, and thus the degree of delamination. Spectra for a set of points along a single test line or test surface can be combined to form spectral surfaces or volumes. This forms the basis for a three-dimensional visualization. The following can be said about advantages of the frequency and depth presentations when linear scales are used for both. The frequency spectral surface/volume emphasizes presence of shallow delaminations, while the thickness spectral surface/volume emphasizes presence of apparent deep reflectors, zones in a serious condition. Because the thickness spectral surface/volume represents a more natural choice for data viewing, a properly selected nonlinear depth scale can provide a well-balanced image for identification of all detected reflectors [6].

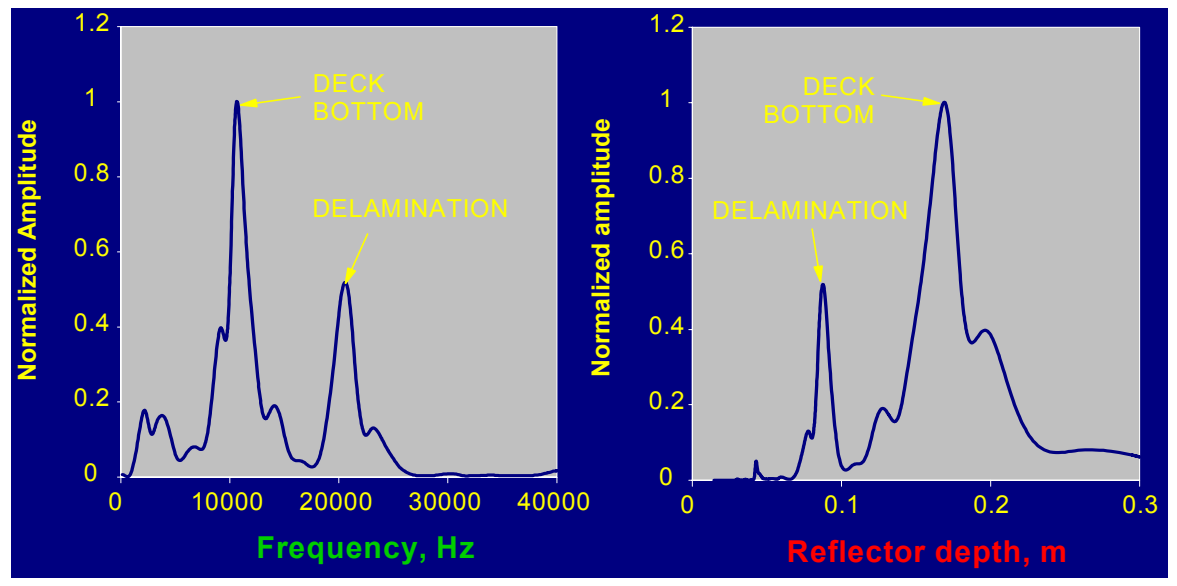

Figure 1. Frequency and thickness/depth spectra.

\subsection{Three-dimensional visualization}

A 3D visualization platform for IE data was developed. Its operation is illustrated in Figure 2 for the deck of the Carter Creek bridge in Virginia. The IE data consists of a reflection value, normalized in the range $[0,1]$, and sampled on a discrete $3 \mathrm{D}$ grid of voxels. Using OpenGL, the data is rendered as a series of texture-mapped planes that slice through the volume, where the reflection strength is used as an index in a colormap look-up table that consists of red, green, blue, and alpha (transparency) values. The user can interactively adjust the transparency so that weaker reflectors become more transparent, allowing better visualization of the strong reflectors. Three sets of reflectors can be noticed: a few shallow reflectors at about $0.1 \mathrm{~m}$ depth representing initial delaminations, a large reflection surface at about $0.2 \mathrm{~m}$ representing reflections from the bottom of the deck, and a number of deep apparent reflectors representing zones in a serious condition. The bridge is mostly in a good condition since the primary reflections are coming from the bottom of the deck.

A procedure that allows translation of those deep reflectors into their actual positions (position of actual delaminations) was developed. The result of this process is illustrated in Figure 3 where the reflector depth limited to a depth slightly larger than the design thickness of the deck. Three distinctive layers can be observed in the figure. The green reflector layer (matching the good condition color) represents reflections from the bottom of the deck. The yellow to orange layer (the fair to poor conditions) represents reflections from shallow reflectors (delaminations). Finally, the red reflector layer (the serious condition color), represents a layer of apparent deep reflectors translated to positions of actual delaminations.

\subsection{Project and network level condition assessment}

Data visualization is very useful for the user to inspect the bridge deck data and thus identify zones of the deck that require repair or rehabilitation. However, this framework also provides analytical software tools that characterize the IE data and provide the overall 
assessment of the condition of a bridge deck for either project level (rehabilitation, repair) and network level (bridge management) evaluation purposes.

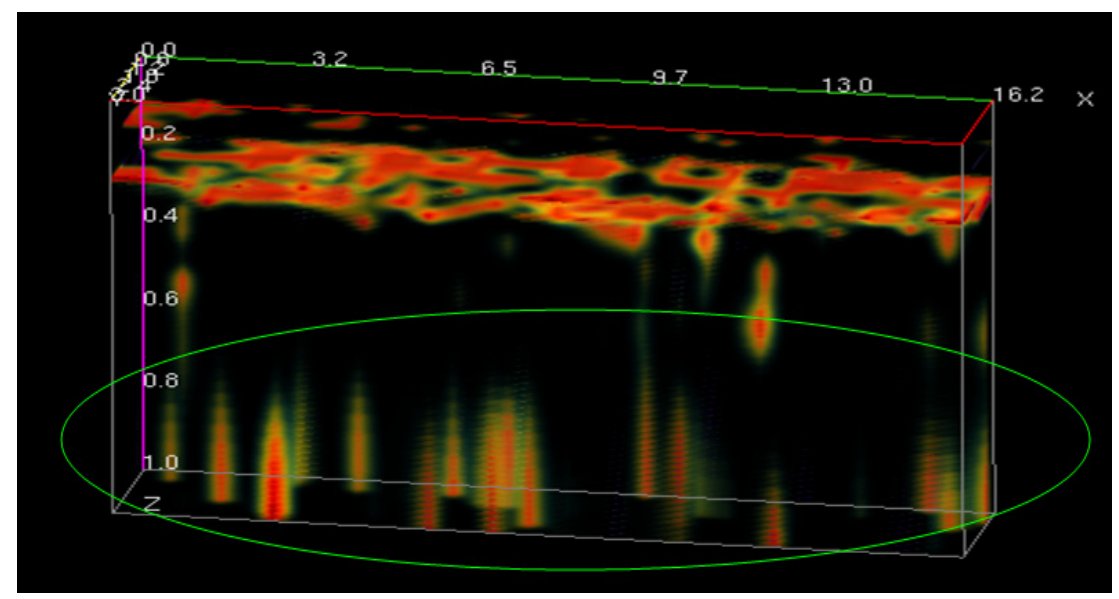

Figure 2. Visualization of the deck of the Carter Creek Bridge, Virginia.

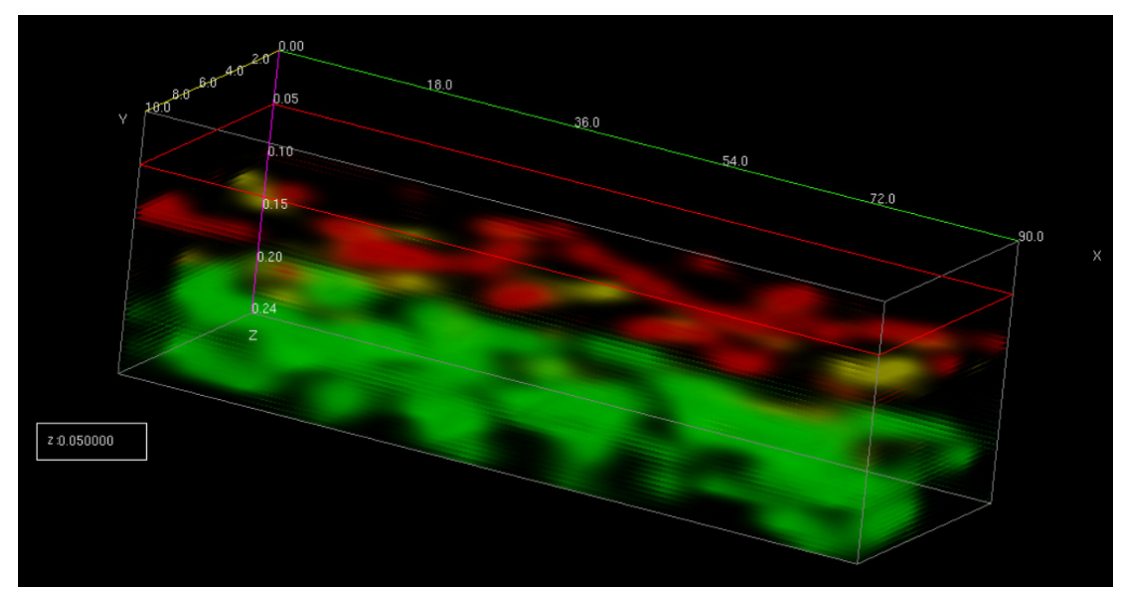

Figure 3. Visualization of the deck of the bridge on interstate I-287over route 1 in Woodbridge, New Jersey.

Images of all three layers of reflectors (green, yellow and red) and the combined reflector image is plotted in a plan view for the deck of the Van Buren bridge in Virginia in Figure 4. The images are plotted together with the condition maps obtained from the traditional approach, in which the spectrum for each test point is examined and the corresponding grade assigned. The condition assessment images point to a deck in a significantly deteriorated condition. This assessment is primarily due to a significant coverage of the deck by deep reflectors (red zones). Presentation of impact echo results in such a form allows for identification of deck areas that will be maintained, rehabilitated or repaired. Since the deck was also evaluated by chain dragging, the IE results were compared to those of the chain drag. The comparison points to similarity of the two approaches in detection of areas with progressed delamination (poor to serious condition), and inability of the chain drag to identify zones of initial delamination (fair to poor grades).

For the purpose of bridge management, or network level rating of bridge decks, it is desirable to describe the deck condition by a single number. Various schemes for automated evaluation of deck rating have been proposed [5], like: reflection intensity vs. depth, cumulative reflection intensity, etc. The most intuitive and most attractive approach to the transportation agencies is illustrated in Figure 5. In this case the condition rating of a bridge 
deck is obtained from a weighted average of the areas of the deck identified to be in the three stages of delamination: sound, fair to poor, and serious. One of the ways how to calculate the rating number is shown in the figure. Certainly, the challenge is to select the right weight factors for the three condition areas. Each transportation agency is expected to suggest different weight factors based on their experience and practice in bridge deck condition assessment, life cycle cost analysis, and maintenance, repair and rehabilitation strategies.
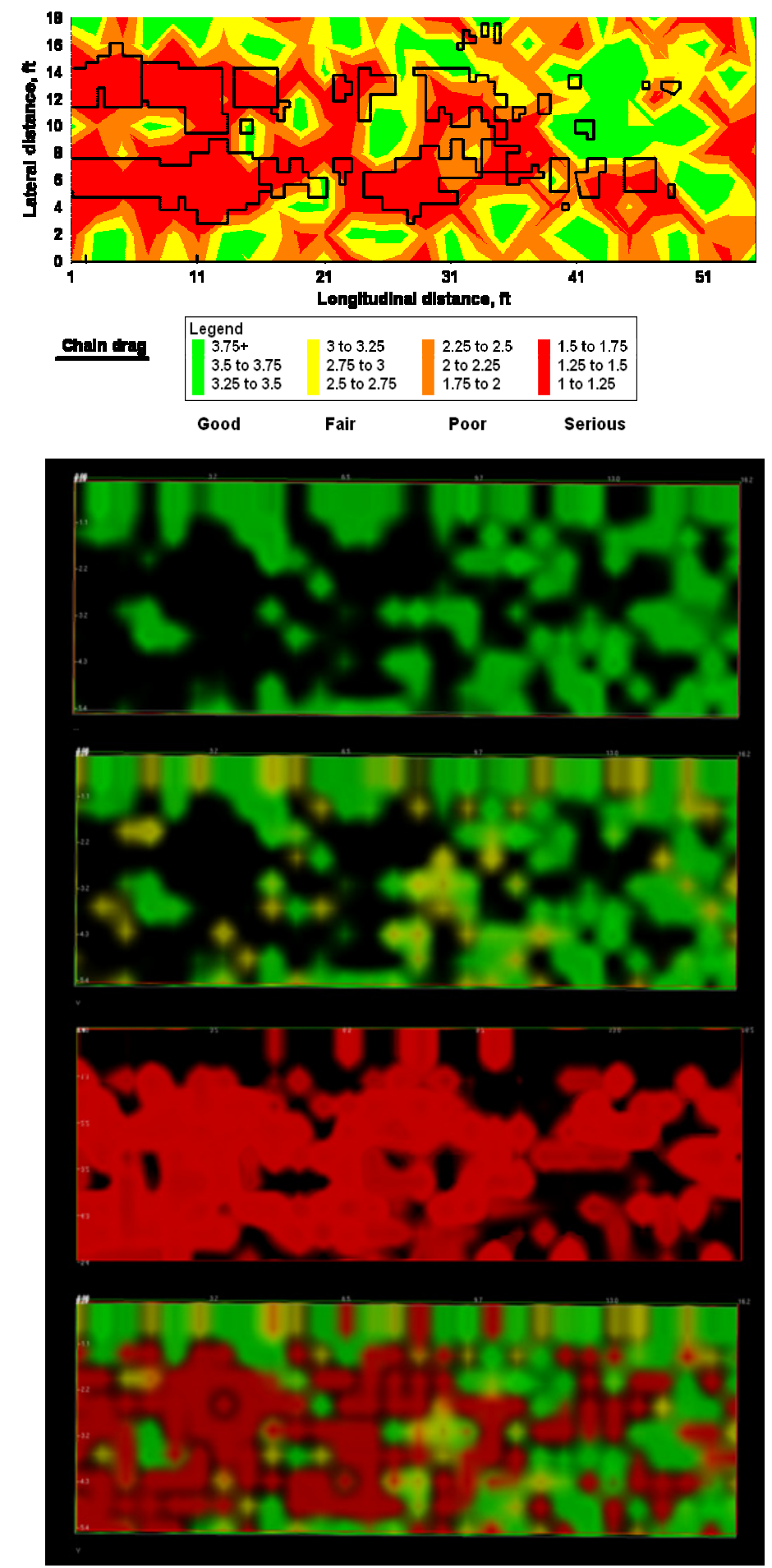

Figure 4. Condition assessment of Van Buren Bridge deck: traditional approach (top), and bottom of the deck, delamination layer, deep reflector layer and combined all reflector layers (bottom). 


\section{Conclusions}

Condition assessment of bridge decks with respect to delamination by IE allows detection of zones of delamination at various stages, from initial to progressed and developed. Advanced data visualization techniques can significantly improve the accuracy and ease of data interpretation through three-dimensional translucent imaging of IE data and separation of important reflector layers. The presented visualization and to it associated interpretation algorithms allow both the overall assessment of the condition of the deck and identification of deteriorated zones of the deck for repair or rehabilitation in an efficient and intuitive way.

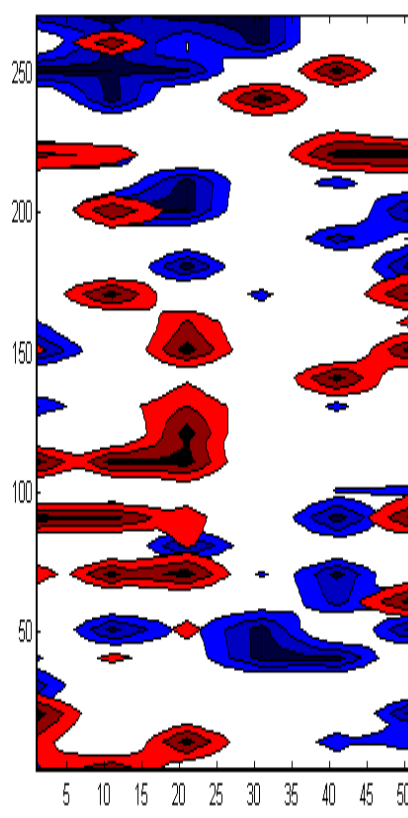

\section{Carter Creek} Grade 72.4

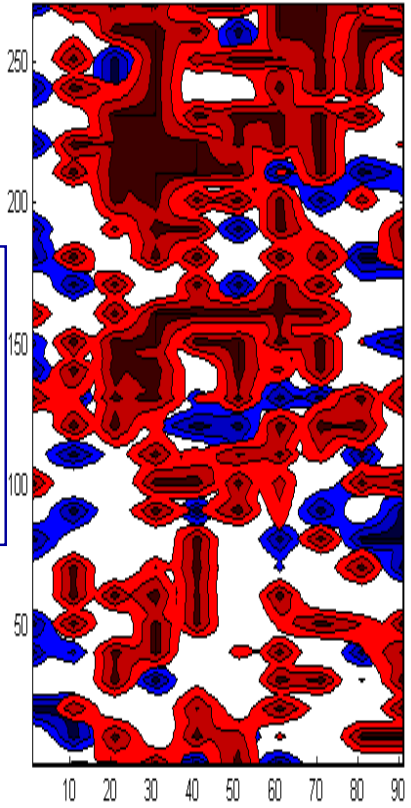

Figure 5. Network level bridge deck rating.

\section{References}

1. Sansalone, M. J. (1993) "Detecting delaminations in concrete bridge decks with and without asphalt overlays using an automated impact-echo field system", Proc. of the British Institute of Non-Destructive Testing International Conference NDT in Civil Engineering, 14-16 April 1993, Liverpool, U.K., pp. 807-820.

2. Carino, N. (2001) "The impact echo method: an overview", Proc. of the Structures Congress and Exposition, American Society of Civil Engineers, Ed by P.C. Chang, 21-23 May 2001, Washington, D.C., on CD-ROM.

3. Gucunski, N., Antoljak, S., Maher, A. (2000) "Seismic methods in post construction condition monitoring of bridge decks", Use of Geophysical Methods in Construction, Geotechnical Special Publ. No. 108, Ed by S. Nazarian and J. Diehl, ASCE, pp. 35-51.

4. Sansalone, M. J., Street, W. B. (1997) "Impact-Echo - Nondestructive Evaluation of Concrete and Masonry", Bullbrier Press, Ithaca, New York.

5. Gucunski, N., Slabaugh, G., Wang, Z., Fang, T., Maher, A. (2008) "Visualization and interpretation of impact echo data from bridge deck testing," Proc. of the $87^{\text {th }}$ Annual TRB Meeting, 13-17 January 2008, Washington, D.C., on CD-ROM.

6. Gucunski, N., Consolazio, G.R., Maher, A. (2006) "Concrete bridge deck delamination detection by integrated ultrasonic methods," Intl. J. Material and Product Technology, Special Issue on NDT and Failure Preventive Technology, Vol. 26., No. 1/2, pp. 19-34. 